Trivent Publishing

(C) The Authors, 2016

Available online at http://trivent-publishing.eu/

Engineering and Industry Series

Volume Power Systems, Energy Markets and Renewable Energy Sources in South-Eastern Europe

\title{
Estimation of Hosting Electric Vehicles Capacity in the Transformers on the Island of Crete
}

\author{
Marianna Dimitropoulou, Antonios Tsikalakis, Antiopi Gigantidou, \\ Emmanuel Thalassinakis, Dionysios Pylarinos
}

\begin{abstract}
Hellenic Electricity Distribution Network Operator (Island Systems Management
Department/Crete-Rhodes Division), Greece

(marianadimitr@gmail.com, a.tsikalakis@deddie.gr, a.gigantidou@deddie.gr, e.thalassinakis@deddie.gr, D.Pylarinos@deddie.gr)
\end{abstract}

\begin{abstract}
Electric Vehicles (EV) penetration gets higher and higher as the battery technology advances and more sophisticated market schemes are proposed. However, increased number of EVs simultaneously charging from the Grid poses also a challenge for the power system operation.

The limitations of the additional demand caused by the charging of EVs on the island of Crete are presented in this paper. Thus, any necessary investments in equipment or more sophisticated control strategies based on the number of the customers served, can be timely scheduled so that the Autonomous Power System of Crete can adapt to the electricity mobility era.
\end{abstract}

\section{Keywords}

Electric Vehicles; Crete; Distribution and Transmission Grid; charging; hosting capacity

This is an Open Access article distributed in accordance with the Creative Commons Attribution Non Commercial (CC-BY-NC-ND 4.0) license, which permits others to copy or share the article, provided original work is properly cited and that this is not done for commercial purposes. Users may not remix, transform, or build upon the material and may not distribute the modified material (http://creativecommons.org/licenses/by-nc/4.0/) 


\section{Introduction}

The environmental awareness as well as the climate change and the constant reduction of the energy resources have led to new technologies in the transport sector. Electric Vehicles (EVs) constitute a constantly developing technology. Surveys have shown that by 2020 there will be a significant raise in the use of Electric Vehicles worldwide, with an average annual increase rate of 59\%. Specifically, by the end of 2020 the total number of passenger vehicles in Greece is estimated at $6,473,000$ of which 129,460 are going to be electric (Hellenic Statistical Authority 2016).

This expected mass penetration into the power grid creates the need for an analysis to define at what extent this additional load, created from the daily charge of EVs, affects the operation of the network. From this point of view it is clear that electric vehicles are not only a technological evolution but also a challenge for the power supply reliability.

In this paper the EVs hosting capacity of the power network of the island of Crete is analysed. The first two paragraphs make an introduction into the main points of Electric vehicles technology and their characteristics. The third paragraph describes the power network of Crete, while the fourth and fifth paragraphs describe the utilized estimation methodologies and their results. In the last paragraph overall conclusions are made along with suggestions for further smart charge control strategies.

\section{Electric vehicles}

An electric vehicle may be powered through a collector system by electricity from off-vehicle sources like the example of trams, or may be self-contained with a battery bank or generator to convert fuel to electricity.

Electric Vehicles can be categorized as Hybrid Electric Vehicles, all electric or battery electric vehicles (BEVs) and Plug-in Hybrid Vehicles, (PHEVs), The latter two categories can be recharged from an external source of electricity either wall sockets or specific charger circuits (Mom, 2012). For our paper we will discuss only about these two categories.

EVs charge from conventional power outlets or dedicated charging stations, a process that typically takes hours, but can be done overnight and often gives a charge that is sufficient for normal everyday usage. There are four main charging methods:

- Mode 1 (AC charging) in which the vehicle is connected to the power grid through standard socket-outlets present in residences, 
- Mode 2 (AC charging, via single-phase or three-phase network) in which the vehicle is connected to the main power grid via household socket-outlets with a cable-incorporated protection device,

- Mode 3 (AC charging) in which the vehicle connects directly to the electrical network via specific socket and plug and a dedicated circuit, and

- Mode 4 (DC charging) in which the electric vehicle is connected to the main power grid through an external charger.

For a slow charge, usually $3.7 \mathrm{~kW} \max$ at $230 \mathrm{~V}$ AC single-phase and max current $16 \mathrm{~A}$, the charging time last between 6-8 hours. For normal charging, up to $7.4 \mathrm{~kW}$ and max current $32 \mathrm{~A}$, the charging time lasts 3-4 hours. On the other hand, a quicker charge at $22 \mathrm{~kW}$ and $400 \mathrm{~V}$ AC three-phase lasts 1-2 hours, while at $43 \mathrm{~kW}$ and $400 \mathrm{~V}$ AC three-phase only 20-30 minutes. Finally, fast charging from 50 to $135 \mathrm{~kW}$ at $400-500 \mathrm{~V} \mathrm{DC}$ can only last 10 minutes.

\section{The Power System of Crete}

\section{A. General description}

Crete is the largest and most populous of the Greek islands, and the fifth-largest island in the Mediterranean Sea. It has an area of $8,303 \mathrm{~km}^{2}$ and as of 2011, the region had a population of 623,065 . The capital and the largest city of the island is Heraklion (Hellenic Statistical Authority 2016). The population is significantly increased during the summer period due to tourists. Many of them rent cars for their transportations and thus Vehicles number is increased. Table 1 provides information on the private passenger Vehicles currently registered in each of the four prefectures of Crete. Private passenger cars are 259 thousand out of the 524 thousand vehicles on the island (Hellenic Statistical Authority 2016).

The island of Crete has the largest autonomous power system in Greece with peak demand about $635 \mathrm{MW}$ and annual energy demand of 3 TWh (HEDNO 2016). A large number of conventional units with different technologies and response characteristics (steam turbines, Internal Combustion Engines (ICE), Open Cycle Gas Turbines (OCGT), and one combined cycle (CC) unit) with total capacity of $824.8 \mathrm{MW}$ have been installed in three power stations, namely Chania, Linoperamata and Atherinolakos, on the island as described in. The total number of generators is 28 . In Table 2, the capacity per unit type and power station is provided. 
Table 1. Registered Passenger Vehicles in each prefecture of the island.

\begin{tabular}{|l|l|}
\hline \multicolumn{1}{|c|}{ Prefecture } & \multicolumn{1}{c|}{ Vehicles } \\
\hline Chania & 57,878 \\
\hline Rethimno & 33,207 \\
\hline Heraklion & 139,460 \\
\hline Lasithi & 28,565 \\
\hline
\end{tabular}

Table 2. Installed capacity (in MW) per unit type and power station

\begin{tabular}{|l|l|l|l|l|l|}
\hline Power station & \multicolumn{1}{|c|}{ Steam } & \multicolumn{1}{|c|}{ ICE } & \multicolumn{1}{|c|}{ OCGT } & \multicolumn{1}{c|}{ CC } & \multicolumn{1}{c|}{ Total } \\
\hline Linoperamata & 111.3 & 49.2 & 118.6 & - & 279.1 \\
\hline Chania & - & - & 202.2 & 132.3 & 334.5 \\
\hline Atherinolakos & 93 & 118.2 & - & & 211.2 \\
\hline Total capacity & 204.3 & 167.4 & 320.8 & 132.3 & 824.8 \\
\hline
\end{tabular}

Crete has one of the highest solar potentials in whole Europe, reaching up to $2100 \mathrm{kWh} / \mathrm{m}^{2} / \mathrm{yr}$, and also a high average wind speed that in many locations exceeds $8.5 \mathrm{~m} / \mathrm{sec}$. These characteristics make the island an ideal place for the installation of wind and solar technologies (Stefanakis 2002). There are more than 1000 small Photovoltaic (PV) parks (mainly of $80 \mathrm{~kW}$ each) and 1800 roof PVs ( $<=10 \mathrm{~kW}$, of about $17 \mathrm{MW})$ installed. Only $5 \mathrm{PV}$ parks have capacity higher than $100 \mathrm{~kW}$ with total capacity about $0.9 \mathrm{MW}$. The largest has capacity 0.3 MW (Gigantidou 2013). There are also 38 wind parks with total installed capacity about $200 \mathrm{MW}$. Currently, the total installed capacity of the Renewable Energy Sources (RES) stations amounts to $296 \mathrm{MW}$ and it is also estimated the development of new RES stations such as Hybrid stations, Solar thermal stations, Geothermal stations and Biomass stations. In 2014 the total yearly RES generation amounted to $575.9 \mathrm{GWh}$, while in 2015 to $638.4 \mathrm{GWh}$, presenting in this way an increase of $33,6 \%$.

The latest overview of the autonomous power system of Crete, which is based on actual operational data from the SCADA system of HEDNO SA, showed that at the time of the island's peak power demand on July 31st. In Fig. 1 the load duration curve of the Cretan Power System for the year 2015 is presented. For only 3 hours there was a high load level (600-660 MW), while for 100 hours the demand exceeds 550MW, and for 2000 hours the demand exceeded 400MW. 




Fig. 1. Demand Curve of the Cretan power System (HEDNO 2015) 
The energy production balance is as shown in Fig. 2 whereas the distribution of demand in each one of the four prefectures of Crete is shown in Fig. 2 (HEDNO 2015).



Fig. 2. Power Generation Breakdown in 2015



Fig. 3. Distribution of Demand per prefecture

\section{B. Substations}

Apart from the main power stations described above, the Cretan power system also includes the $150 \mathrm{kV}$ Power Transmission Network. It consists of 21 substations- 4 of them serving production units only- and about $600 \mathrm{~km}$ of Over Head Lines. The name, the installed capacity of the transformers and the peak power demand of each substation are presented in Table 3 (HEDNO 2015). 
Table 3. Characteristics of the Cretan $150 \mathrm{kV}$ transmission substations (year 2015)

\begin{tabular}{|c|c|c|c|}
\hline Substation & $\begin{array}{c}\text { Installed } \\
\text { Transformers } \\
\text { Capacity } \\
\text { (MVA) }\end{array}$ & $\begin{array}{c}\text { Peak Power } \\
\text { Demand Av. } \\
\text { hourly } \\
\text { (MW) }\end{array}$ & \multirow{5}{*}{$\begin{array}{l}\text { Moires } \\
\text { Pretoria } \\
\text { Rethimno } \\
\text { Chania }\end{array}$} \\
\hline Sitia & $2 \times 12.50$ & 18.3 & \\
\hline Ierapetra & $2 \times 25.00$ & 27.2 & \\
\hline Ag. Nicolaos & $2 \times 50.00$ & 39.3 & \\
\hline Stalida & $2 \times 50.00$ & 66.5 & \\
\hline Heraklion I & $2 \times 50.00$ & 61.3 & Kastelli \\
\hline Heraklion II & $3 \times 50.00$ & 85.9 & Agyia \\
\hline Heraklion III & $2 \times 50.00$ & 41.7 & Vrises \\
\hline Linoperamata & $1 \times 25.00$ & 18.6 & \\
\hline
\end{tabular}

Installed
Capacity of
Transformers
(MVA)

$2 \times 25.00$

$2 \times 25.00$

$2 \times 25.00 \&$

$1 \times 50.00$

$3 \times 50.00$

$2 \times 25.00$

$2 \times 50.00$

$2 \times 25.00$
Peak

Power

Demand

Av. hourly

(MW)

28.4

18.6

71.8

102.8

23.9

31.2

16.4

\section{Methodology}

The results of the estimated limitations of the additional power demand caused by the charging of EVs in the various High Voltage substations on the island of Crete are based on 3 comparative methodologies presented in the following subsections.

\section{A. Comparison between installed capacity and peak demand}

The first methodology is based upon the comparison between the installed capacity and the peak demand for each unit type, power station and the whole island. The balance of the two values gives the limitations of the additional power demand for the three cases.

\section{B. Comparison between substation capacity and peak demand}

The second methodology that estimates the hosting capacity of EVs in the power network of Crete is based on the installed capacity of the substation transformers along with the substation peak demand (average hourly). In this case the worstcase scenario is considered; the transformers operate with no ventilation in order to take into account their lowest installed capacity and the power factor is considered 0.95 . 


\section{The case of transformer fault}

The last methodology includes the capacity estimation in case of one of the transformers complete loss. The values that are again taken into account are the remaining installed capacity of the substation transformers and the substation peak demand (average hourly). Thus the $\mathrm{N}-1$ criterion for the substation can be evaluated.

\section{Results}

The possibility of two types of charging processes; slow and fast, is examined in the produced results. As mentioned in section 2, a slow full charge $(3.7 \mathrm{~kW} / \mathrm{h})$ for a typical battery of $22 \mathrm{kWh}$ is considered to last about 6 hours while a fast full charge $(50 \mathrm{~kW} / \mathrm{h}) 10-30$ minutes.

\section{A. First methodology}

If the total capacity of RES, currently 296.4 MW, was exploited based on the calculations of the first methodology, the number of charging EVs that could simultaneously penetrate into the power system of the whole island amounts to: 131,324 slow charging EVs or 9,718 fast charging EVs. However, rather often RES do not participate so much in meeting the demand since unfortunately the annual peak demand takes place when the wind power is rather low and sometimes in the early evening hours when no sunshine exists. In such a case the number of EVs that could simultaneously be charged is dramatically decreased to 32,133 slow charging vehicles or 2,378 Fast Charging Vehicles.

\section{B. Second methodology}

The total installed capacity of the transformers on the island of Crete is 1,250 MVA. In order to consider the worst-case scenario, the installed capacity of the transformers without ventilation is estimated to 1,005 MVA. As a result, the hosting EVs capacity in the transformers of the island of Crete is 83,810 slow charging vehicles or 6,202 fast charging vehicles.

The EV capacity in the transformers of each Prefecture of the island is as shown in Table 4 . This is the maximum achievable capacity provided that reconfiguration of the Distribution Grid in each prefecture can be made. Thus, lack of capacity in one of the substations in each prefecture could be mitigated by serving its feeders by a nearby substation. However, such a scenario can be rather optimistic and requires additional investments in the Distribution Grid. 
Table 4. Transformers hosting capacity of EVs per Cretan prefecture

\begin{tabular}{|l|l|l|l|l|l|}
\hline Substation & $\begin{array}{c}\text { Installed } \\
\text { Capacity of } \\
\text { Transformers }\end{array}$ & $\begin{array}{c}\text { Peak Power } \\
\text { Demand Av. } \\
\text { hourly }\end{array}$ & $\begin{array}{c}\text { Available } \\
\text { Power }\end{array}$ & \multicolumn{2}{|c|}{ Number of EVs } \\
\cline { 2 - 6 }$(\boldsymbol{M V A})$ & $(\boldsymbol{M W})$ & $(\boldsymbol{M W})$ & $\begin{array}{c}\text { Slow } \\
\text { charging }\end{array}$ & $\begin{array}{c}\text { Fast } \\
\text { charging }\end{array}$ \\
\hline Chania & 320 & 174.3 & 129.7 & 35,054 & 2,594 \\
\hline Rethimno & 80 & 71.8 & 4.2 & 1,135 & 84 \\
\hline Heraklion & 460 & 321 & 116 & 31,351 & 2,320 \\
\hline Lasithi & 145 & 84.8 & 60.2 & 13,295 & 984 \\
\hline
\end{tabular}

The number of EVs that could be charged by each substation without neither additional investment on the Distribution Grid, nor investment on Distributed Generation is described in Table 5. In order to face even more adverse conditions, it is considered that no ventilation takes place. Prefecture Chania and Lasithi are the ones with the highest reduction in available capacity by 10,272 and 1,962 slow charging EVs or by 760 and 145 EVs respectively.

Table 5. Transformers hosting capacity of EVs per Cretan transmission substation - without ventilation

\begin{tabular}{|l|l|l|l|l|l|}
\hline Substation & $\begin{array}{c}\text { Installed } \\
\text { Capacity of } \\
\text { Transformers }\end{array}$ & $\begin{array}{c}\text { Peak Power } \\
\text { Demand Av. } \\
\text { hourly }\end{array}$ & $\begin{array}{c}\text { Available } \\
\text { Power }\end{array}$ & \multicolumn{2}{|c|}{ Number of EVs } \\
\cline { 2 - 6 }$(\boldsymbol{M V A})$ & $(\boldsymbol{M W})$ & $(\boldsymbol{M W})$ & $\begin{array}{c}\text { Slow } \\
\text { charging }\end{array}$ & $\begin{array}{c}\text { Fast } \\
\text { charging }\end{array}$ \\
\hline Sitia & 20 & 18.3 & 1.7 & 459 & 34 \\
\hline Ierapetra & 40 & 27.2 & 10.8 & 2,918 & 216 \\
\hline Ag. Nicolaos & 80 & 39.3 & 36.7 & 9,918 & 734 \\
\hline Stalida & 80 & 66.5 & 9.5 & 2,567 & 190 \\
\hline Heraklion I & 80 & 61.3 & 14.7 & 3,972 & 294 \\
\hline Heraklion II & 120 & 85.9 & 28.1 & 7,594 & 562 \\
\hline Heraklion III & 80 & 41.7 & 34.3 & 9,270 & 686 \\
\hline Linoperamata & 20 & 18.6 & 0.4 & 108 & 8 \\
\hline Moires & 40 & 28.4 & 9.6 & 2,594 & 192 \\
\hline Pretoria & 40 & 18.6 & 19.4 & 5,243 & 388 \\
\hline Rethimno & 80 & 71.8 & 4.2 & 1,135 & 84 \\
\hline Chania & 120 & 102.8 & 11.2 & 3,027 & 224 \\
\hline Kastelli & 40 & 23.9 & 14.1 & 3,810 & 282 \\
\hline Agyia & 80 & 31.2 & 44.8 & 12,108 & 896 \\
\hline Vrises & 40 & 16.4 & 21.6 & 5,837 & 432 \\
\hline
\end{tabular}




\section{Third methodology}

The results of the third methodology give the capacity estimation of EVs for each substation of the island in case one of its transformers gets out of service. Table 6 presents the results considering transformers operation with ventilation. The slow charging capacity is 14,024 and the fast charging one is 1,038 . One prefecture, Rethimno, could not meet its demand in such a case unless a small transformer fails and extensive reconfiguration of feeders takes place. Clearly under N-1 criterion much fewer EVs can be charged. A comparison of the capacity per Prefecture is shown in Fig. 4 for all the cases studied.

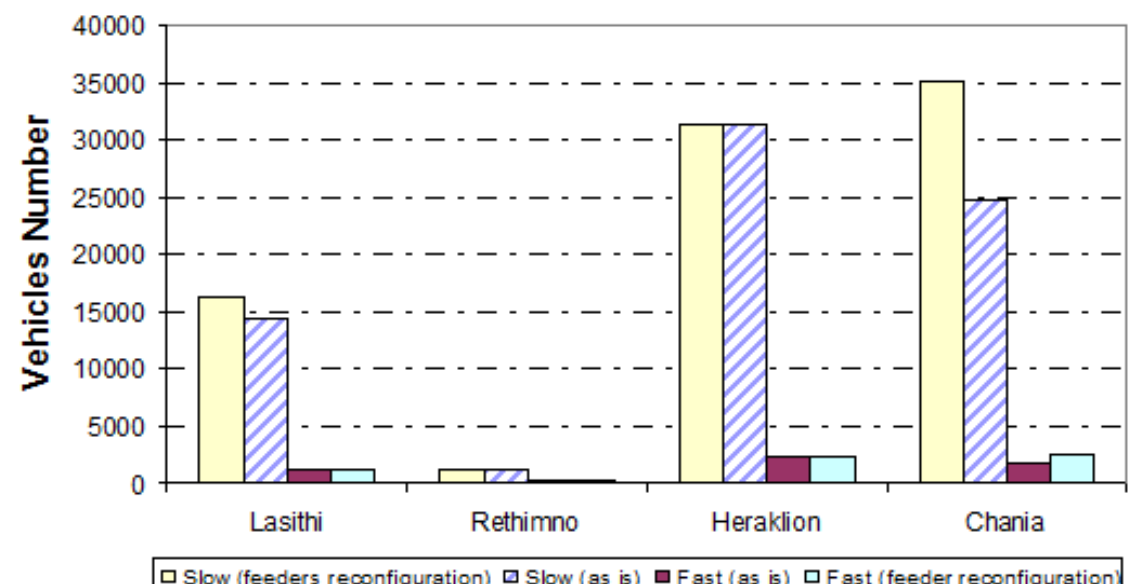

Fig. 4. Number of EVs per prefecture for simultaneous charge

Table 6. Hosting capacity of EVs in case of transformer loss

\begin{tabular}{|l|l|l|l|l|l|}
\hline Substation & $\begin{array}{c}\text { Installed } \\
\text { Capacity of } \\
\text { Transformers }\end{array}$ & $\begin{array}{c}\text { Peak Power } \\
\text { Demand Av. } \\
\text { hourly }\end{array}$ & $\begin{array}{c}\text { Available } \\
\text { Power }\end{array}$ & \multicolumn{2}{|c|}{ Number of EVs } \\
\cline { 2 - 6 }$(\boldsymbol{M V A})$ & $(\boldsymbol{M W})$ & $(\boldsymbol{M W})$ & $\begin{array}{c}\text { Slow } \\
\text { charging }\end{array}$ & $\begin{array}{c}\text { Fast } \\
\text { charging }\end{array}$ \\
\hline Sitia & 12.5 & 18.3 & - & - & - \\
\hline Ierapetra & 25 & 27.2 & - & - & - \\
\hline Ag. Nicolaos & 50 & 39.3 & 8.2 & 2,216 & 164 \\
\hline Stalida & 50 & 66.5 & - & - & - \\
\hline Heraklion I & 50 & 61.3 & - & - & - \\
\hline Heraklion II & 100 & 85.9 & 9.1 & 2,459 & 182 \\
\hline Heraklion III & 50 & 41.7 & 5.8 & 1,567 & 116 \\
\hline Linoperamata & 0 & 18.6 & - & - & - \\
\hline Moires & 25 & 28.4 & - & - & - \\
\hline Pretoria & 25 & 18.6 & 5.15 & 1,391 & 103 \\
\hline Rethimno & $75 / 50$ & 71.8 & $-/-$ & $-/-$ & $-/-$ \\
\hline
\end{tabular}




\begin{tabular}{|l|l|l|l|l|l|}
\hline Chania & 100 & 102.8 & - & - & - \\
\hline Kastelli & 25 & 23.9 & - & - & - \\
\hline Agyia & 50 & 31.2 & 16.3 & 4,405 & 326 \\
\hline Vrises & 25 & 16.4 & 7.35 & 1,986 & 147 \\
\hline
\end{tabular}

\section{Results and Conclusion}

The power supply performance and reliability along with the potential impacts of uncontrolled EVs charge on system operation, is an issue for any utility worldwide, especially for non-interconnected power systems. Additionally to peak demand increase at power system level, considerable change of the loading of HV/MV substations is expected. Three methodologies were used in order to estimate the hosting capacity of charging EVs in the autonomous power grid of the island of Crete. Our data processing, based on the installed capacity of each power station and transmission substation and the peak demands (first and second methodology), has shown that 14,024 slow charging EVs could simultaneously be charged by the Cretan power system even at N-1 criterion of all transformers. On the other hand, the number for fast charging is considerably lower at 1,038 EVs. At peak demand even if all the transformers work properly, the conventional units could lead in charging simultaneously 32 thousand vehicles in slow charge mode, i.e. about $1 / 8^{\text {th }}$ of the passenger vehicles on the island.

Interestingly, the third methodology shows that only 6 out of the 15 substations that are considered could host a number of EVs in case of a transformer loss and peak demand. From Table 6, it is clear that the substations of the most rural areas of the island (Agyia, Pretoria and Kastelli) have the capability of hosting a specific number of charging EVs.

Considering at the same time that in the next few years there will be a significant increase in the use of electric vehicles not only in Crete but in the whole country, appropriate Network planning, generation expansion and control strategies are necessary in an effort to meet the additional peak demand. The results for the transformers hosting capacity per Cretan prefecture (Fig. 4) show that a rearrangement of the island's distribution grid infrastructure could be useful in order to increase the hosting capacity of the substations. Consequently, additional researches and advanced charge control strategies need to take into account also congestions in the distribution grid (MV and LV). Moreover extensive fast charging should be avoided so as to avoid sudden stress of the grid.

Control strategies could mitigate the need of reinforcing substation equipment since not all the vehicles will charge simultaneously, reduce the 
amount of investment or even postpone reinforcements in case of considerable penetration levels (Karfopoulos and Hatziargyriou 2013) A first step in this direction could be the implementation of a sequential charging pattern at the vehicles that are connected to the grid. In this way, the number of vehicles that could be charged over an hour can be doubled. Also, most charging could occur overnight using the most efficient off-peak base load sources. Another step in this direction could be the application of smart charging limitations especially when there are high power demands or in cases when the networks operate close to their limits or in order to maintain equipment. The control strategies could also maximize the penetration of RES and combine charging when RES production is high.

Such solutions could help increase the penetrations of EVs on the island of Crete mitigating the impact of EVs in generation and transmission network equipment.

\section{References}

Gigantidou, Antiopi. 2013. "Renewable energy sources in Crete." Paper presented in the 2013 IREP Symposium Bulk Power System Dynamics and Control-IX Optimization, Security and Control of the Emerging Power Grid.

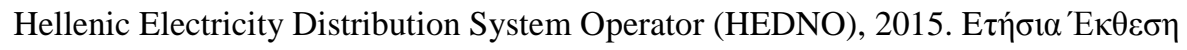

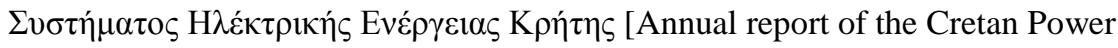
System], 2015.

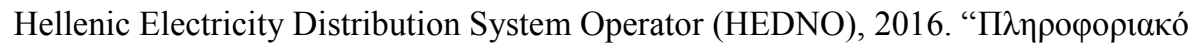

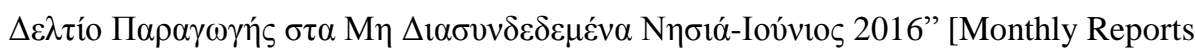
of RES \& Thermal Units in the non-Interconnected Islands], Last Modified at $20^{\text {th }}$ September 2016, http://www.deddie.gr/en/themata-tou-diaxeiristi-midiasundedemenwn-nisiwn/miniaia-deltia-ape-kai-thermikis-paragwgis-sta-midiasundedemena-nisia/2016.

Hellenic Statistical Authority, 2016, "Population and Social Conditions", Last modified June $9^{\text {th }}$ 2016, http://www.statistics.gr/en/statistics/pop.

Karfopoulos, Evangelos L., and Nikos D. Hatziargyriou. "A multi-agent system for controlled charging of a large population of electric vehicles." IEEE Transactions on Power Systems 28, No. 2 (2013): 1196-1204.

Mom, Gijs. The electric vehicle: Technology and expectations in the automobile age. The John Hopkins University Press, Baltimore 2012.

Stefanakis, John. 2002, “Crete: An ideal case study for increased wind power penetration in medium sized autonomous power systems.", Paper presented in the In IEEE Winter Meeting. 2002. 